\title{
Article
}

http://dx.doi.org/10.11646/phytotaxa.207.3.5

\section{A comparative study of Pleurosigma subrectum and $P$. acus (Bacillariophyta)}

\author{
FRITHJOF A.S. STERRENBURG ${ }^{1, *}$, STUART R. STIDOLPH ${ }^{2}$, EUGENIA A. SAR $^{3} \&$ INÉS SUNESEN $^{3}$ \\ ${ }^{1}$ Stationsweg 158, 1852LN Heiloo, the Netherlands. \\ ${ }^{2} 3 / 15$ Gebbie Rd., Taradale, Napier, New Zealand. \\ ${ }^{3}$ División Ficología, Facultad de Ciencias Naturales y Museo, Universidad Nacional de La Plata, Paseo del Bosque s/n, 1900 La Plata, \\ Argentina. \\ *Corresponding author (e-mail: fass@wxs.nl)
}

\begin{abstract}
In continuation of an earlier paper on Pleurosigma species with an (almost) non-sigmoid valve and raphe sternum, a comparative study was made in LM and SEM of Pleurosigma subrectum and P. acus. For P. subrectum, slides and a subsample of the type material were examined. For $P$. acus no unmounted material permitting SEM investigation is extant; a sample containing specimens fully matching the type in LM was therefore used as epitype material for SEM. The original data on striation of $P$. acus are emended. No morphological differences indicating separate specific status of these two taxa were observed and $P$. acus is therefore here designated a heterotypic synonym of $P$. subrectum. From the data now available, this is a very widely distributed species. The study demonstrates the indispensable role of collections for investigations on the diversity and distribution of diatom species.
\end{abstract}

Key words: diatoms, Pleurosigma, P. acus, P. subrectum, taxonomy, type material

\section{Introduction}

In Sar et al. (2012) a study was made of a group of species of Pleurosigma W. Smith (1852: 2, in part, nom. cons.) with (almost) non-sigmoid valves and raphe sternum. It was shown that a sigmoid outline is not a generic character of Pleurosigma, as the non-sigmoid species examined and the sigmoid species in the genus show an identical general morphology: sandwich-type valve consisting of a basal (interior) layer with more or less round areolar openings and a tegumental (exterior) layer with very narrow longitudinal fissures, arranged in three (transverse and two oblique) stria systems.

In Sterrenburg et al. (2005) a SEM study was made of valve morphogenesis in some Pleurosigma species including the non-sigmoid P. acus A. Mann (1925: 132) and it was found that the valve structure of Pleurosigma is not loculate ("divided into separate compartments by septa"). The two valve layers are shored by short pillars, found to be hollow in two different species, so that there are no septa and the valve interior consists of an open space resembling a parkinggarage.

Two characteristic non-sigmoid Pleurosigma taxa described from climatologically very different regions are $P$. subrectum Cleve in Cleve \& Grunow (1880: 14, 53) from Arctic waters and P. acus from the Philippines. The former appears to have vanished from the literature since the $19^{\text {th }}$ century; the type material of the latter was examined in Stidolph (2002) and the data were used in Sterrenburg et al. (2005) for identification of specimens from the Pacific coast of the USA. The sum total of information so far available for these two taxa appears to be as follows:

\section{For P. subrectum:}

- $\quad$ The protologue (Cleve \& Grunow 1880: 14, 53) mentions the valve outline, the raphe-sternum pattern and the striation; a drawing (Cleve \& Grunow 1880: pl. 3, fig. 72) depicts a specimen that is either tilted or distorted as it is clearly asymmetric. As usual, no holotype is designated.

- $\quad$ Peragallo (1891: 14) quotes the data in Cleve \& Grunow (1880) adding that it is larger and more coarsely striated "than the type". However, by "the type" he means P. intermedium W. Smith (1853: 64), a wholly different species-see 
Sar et al. (2012). A drawing (Peragallo 1891: pl. 5, fig. 30) again depicts a specimen that is apparently distorted as it is asymmetric.

- Cleve (1894: 35) merely gives dimensions for a single specimen and data on striation and mentions it as a variety of $P$. nubecula W. Smith (1853: 64) — which is a synonym of $P$. intermedium W. Smith (see Sar et al. 2012). There is no illustration.

- In the catalogue supplied with the set of slides Cleve \& Möller (1877-1882), the species is mentioned for the material "Finnmark, Maasö", slides \#312 and \#313. The locality Maasö is currently named Masoy.

For. P. acus:

- The protologue (Mann 1925: 132) is very cursory. The two photomicrographs (Mann 1925: pl. 29, figs. 4-5) show just enough detail to conclude that the data on striation given are totally at variance with the specimen illustrated — see under Observations.

- The holotype has been lost, but Stidolph (2002: 274, figs 1-5) gives photomicrographs in LM with modern equipment of 2 specimens from the original material, one of which he designated the syntype.

- Sterrenburg et al. (2005) used the type data in Stidolph (2002) to identify specimens from the Pacific coast of the USA. In Sterrenburg (1991) striae intersection angles were given for specimens identified as P. acus by comparison with Mann's original photomicrographs.

Type material of these taxa has never been examined in SEM, thus the available information cannot be regarded as sufficient for reliable modern taxonomy. This, therefore, is a choice example of the necessity of research in wellcurated collections to obtain an insight into questions of the diversity and distribution of diatom species.

\section{Materials and methods}

Materials:-For P. subrectum, the following were examined:

- Naturhistoriska Riksmuseet, Stockholm, Sweden (S): two slides (S 123001-01 and S 123001-02) of the original material by Cleve \& Möller, "Finnmark, Maasö", \#312 and \#313, were examined, isolectotype specimens were marked with ink rings. No material is present for SEM.

- Natural History Museum, London, UK (BM): in slide Cleve \& Möller \#312, Deby collection, BM 13071, "Finnmark, Maasö", slide coordinates for several isolectotype specimens were determined (see under Description). No material is present for SEM.

- $\quad$ Friedrich-Hustedt-Center for Diatom Research, Bremerhaven (BRM, Germany). The collection yielded a small quantity of the material "E251, Finnmark, Maasö, a, P.T. Cleve, 12.1881, von E. Weissflog", a subsample of Cleve \& Moeller (1877-1882) \#312. This was a particularly fortunate find; the material is in good condition and made examination in SEM possible. A small portion of the material was used for preparation of a slide in Naphrax. In this slide a marked specimen is here designated the lectotype as no holotype was indicated at the time of publication.

- $\quad$ For P. acus, the materials examined were:

- Albert Mann Collection, National Museum of Natural History, Smithsonian Institution, USA, slides \#3278 (syntype designated in Stidolph 2002) and \#3279 (lectotype designated here). No material is present for SEM in this collection or known to be extant elsewhere.

- As no material is left for SEM, a search was made for specimens matching the data for the type. These were found in the material "Toque-Toque Grande Beach, Sao Sebastiao, Sao Paulo, Brazil", collection Sterrenburg \#724 (eventually in BRM), also deposited in Instituto de Botanica de Sao Paulo (\#SP428.775). This is here designated the epitype material.

- Reference is also made to the material "Bird Rock, La Jolla, Calif. USA, March 22, 2002" examined in Sterrenburg et al. (2005), which contained specimens matching Mann's photomicrographs of the type of $P$. acus in LM.

Methods:- -New slides and stubs were prepared with the usual methods as in Sar et al. (2012). LM photomicrographs were taken with planapochromatic objectives, in brightfield (BF) or DIC, as indicated in the legends for the illustrations. The images of the lectotype of $P$. acus are positive scans of Kodak 2415 negatives, all other LM images were taken with a $10 \mathrm{Mp}$ digital camera. In one case a stack of 6 separate DIC images was made, as specified in the legends. Slide coordinates were determined as described in Sterrenburg et al. (2012). The "stria angle" is the angle between the two oblique stria systems. 


\section{Taxon descriptions}

Pleurosigma subrectum Cleve in Cleve \& Grunow (1880: 53, pl. 3, fig. 72) (Figs. 1-6: LM, 7-11: SEM)

Lectotype:-“E251, Finnmark, Maasö, a, P.T. Cleve, 12.1881, von E. Weissflog” here designated, geographic coordinates $71^{\circ} 00^{\prime} \mathrm{N}, 2^{\circ} 00^{\prime} \mathrm{E}$. BRM! ZU 9/91, slide coordinates 3.2 E, $6.0 \mathrm{~S}$. This material is a subsample of Cleve \& Möller (1877-1882) \#312, "Finnmark, Maasö".

Isolectotypes:- In slide BM 13071 at slide coordinates $6.4 \mathrm{E}, 5.7 \mathrm{~S} ; 11.8 \mathrm{E}, 8.4 \mathrm{~S} ; 11.4 \mathrm{E}, 7.8 \mathrm{~S} ; 4.6 \mathrm{E}, 8.0 \mathrm{~S}$ and 10.1 E, 12.0 S; also marked on slides S 123001-01 and S 123001-02.

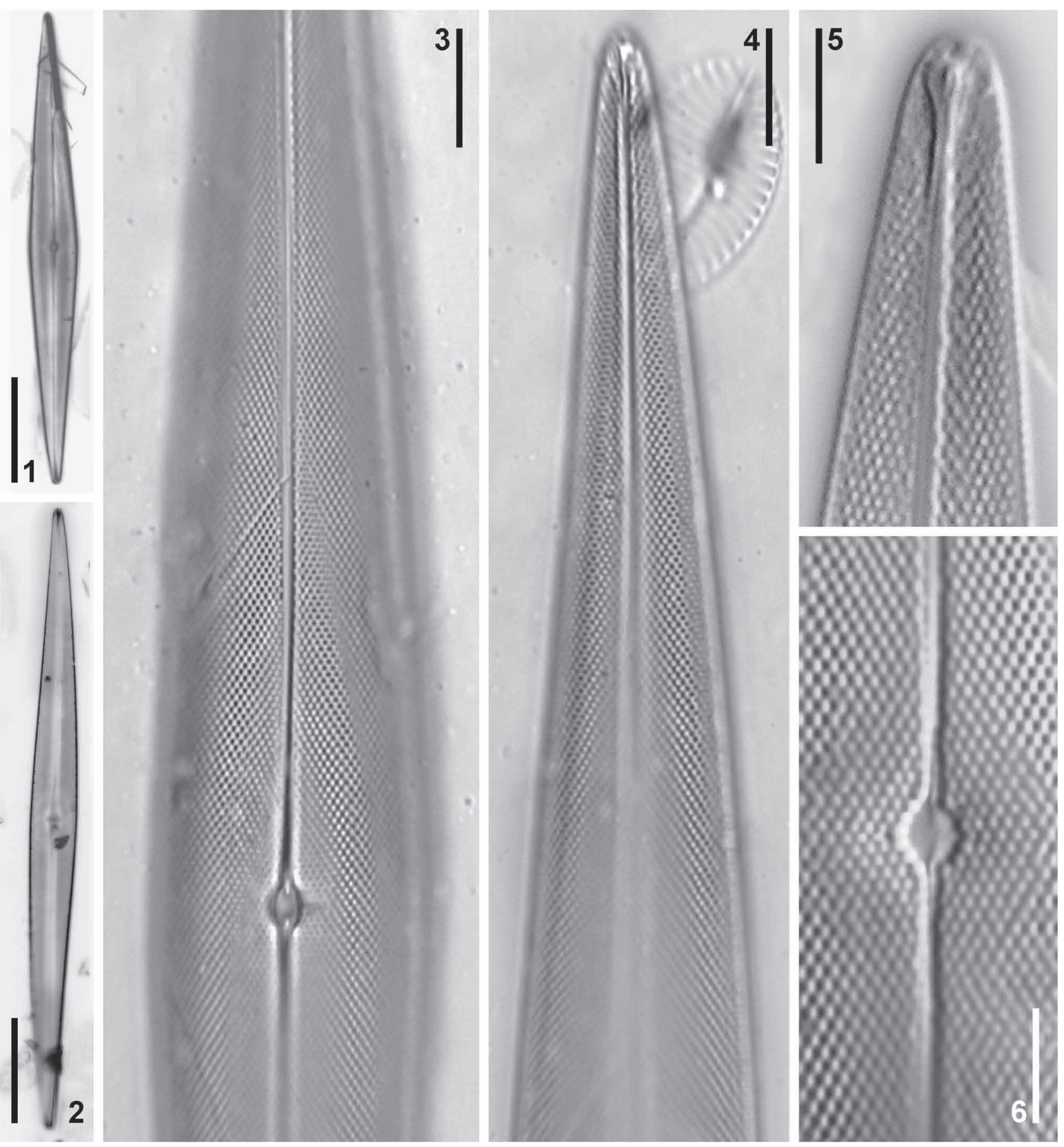

FIGURES 1-6. Pleurosigma subrectum, type material, LM. 1, 2. Survey of small and large specimens. 3-6. Lectotype specimen. All BF except Fig. 5, DIC, stack of 6 images. Scale bars $=50 \mu \mathrm{m}$ (Figs. 1, 2), $10 \mu \mathrm{m}$ (Figs. 3, 4), $5 \mu \mathrm{m}$ (Figs. 5, 6).

LM description:-Valves fusiform, non-sigmoid (Figs. 1-4), ca. 160-280 $\mu \mathrm{m}$ long, 18-22 $\mu \mathrm{m}$ wide, with acute apices. Raphe sternum non-sigmoid throughout but helictoglossae very slightly deflected (Fig. 5). Striae transverse $c a$. 
19-21 in $10 \mu \mathrm{m}$, oblique $c a$. 15-18 in $10 \mu \mathrm{m}$, stria angle $63-68^{\circ}$ (Fig. 6). Central area small, round (Figs. 3, 6). Central raphe fissures long, almost overlapping and slightly undulating (Fig. 6).

SEM description:-Externally, central raphe fissures long, deflected to the same side, almost overlapping (Fig. 7). Apical raphe fissures sharply deflected and terminally strongly recurving forming a hook (Fig. 8). A long accessory fissure terminates within this hook (Fig. 8, bottom arrow) and there is an accessory apical pore (Fig. 8, top arrow). Internally, areolar openings generally bisected by a small bar (Fig. 9-see also inset, Fig. 10) except around the elevated central raphe nodule, which is enclosed within two small central bars of approximately equal length (Fig. 9). Helictoglossa prominent, slightly deflected, near the tip there is a small apical pore (Fig. 10, arrow). Basal and tegumental layers joined by columns (Fig. 11), which are hollow (white arrow in Fig. 11) and showing tiny additional cavities (black arrows in Fig. 11).
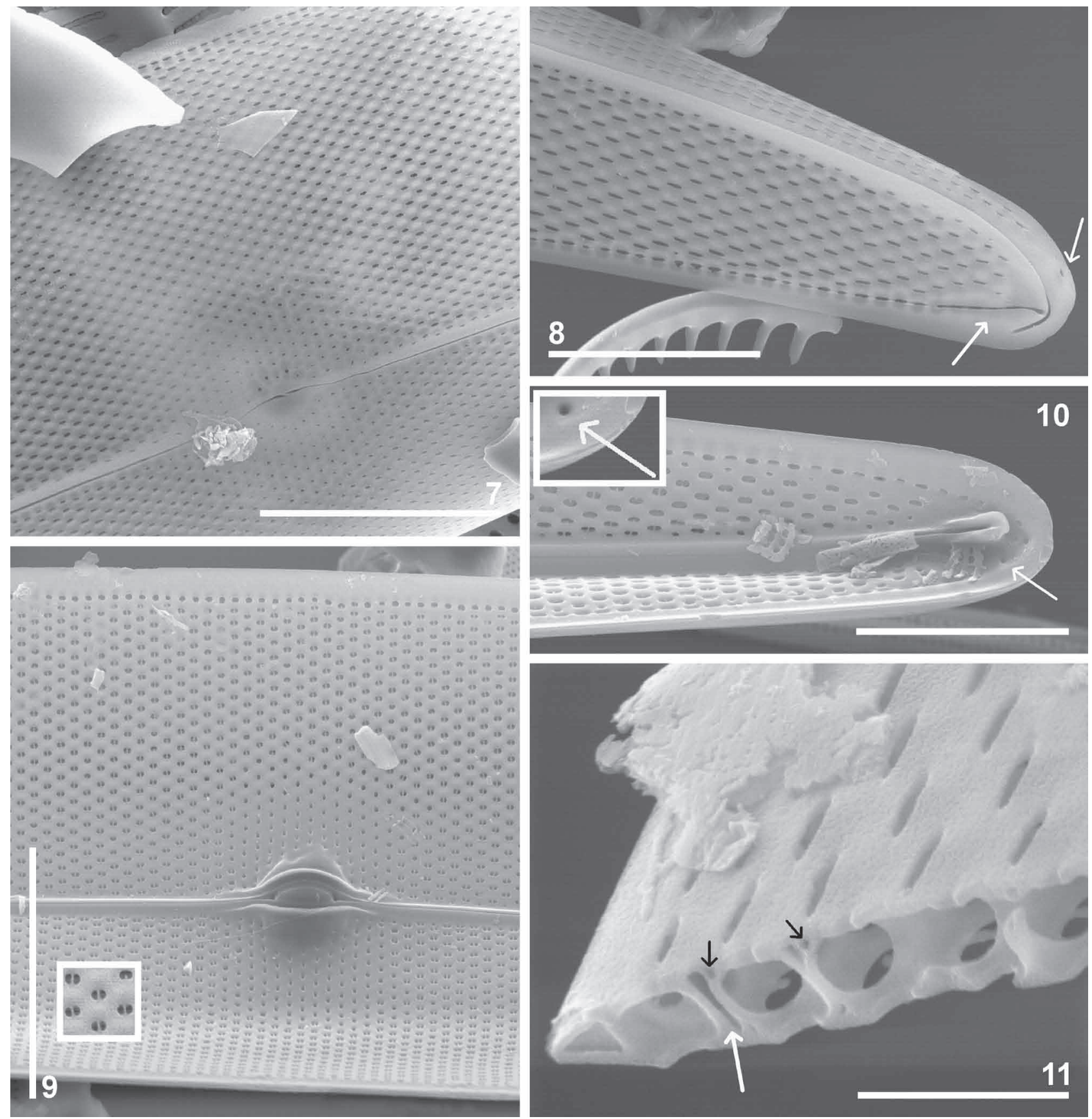

FIGURES 7-11. Pleurosigma subrectum, type material, SEM. Fig. 7. Valve centre, external. Central raphe fissures almost overlap. Fig. 8. Valve apex, external. Top arrow marks apical pore, bottom arrow marks accessory fissure terminating within raphe "hook". Fig. 9. Valve centre, internal. Note double areolar openings (see enlarged inset) and elevated central raphe nodule. Fig. 10. Valve apex, internal. Prominent helictoglossa, arrow marks apical pore (see enlarged inset). Fig. 11. Broken valve shows hollow columns (white arrow) with additional minute cavities (black arrows). Scale bars $=10 \mu \mathrm{m}$ (Figs 7, 9), $5 \mu \mathrm{m}$ (Figs 8, 10), $1 \mu \mathrm{m}$ (Fig. 11). 
Habitat:-Littoral marine.

Distribution:-Type material North Scandinavian coast, specimens matching the type were personally observed in materials from the UK, Spain, W. coast of the USA and Brazil.

Observations:-The species is fairly common in the type material, 20 intact specimens were seen in the 4 slides examined. The hollow columns joining the basal and tegumental layers are a particularly noteworthy finding - see under $P$. acus.
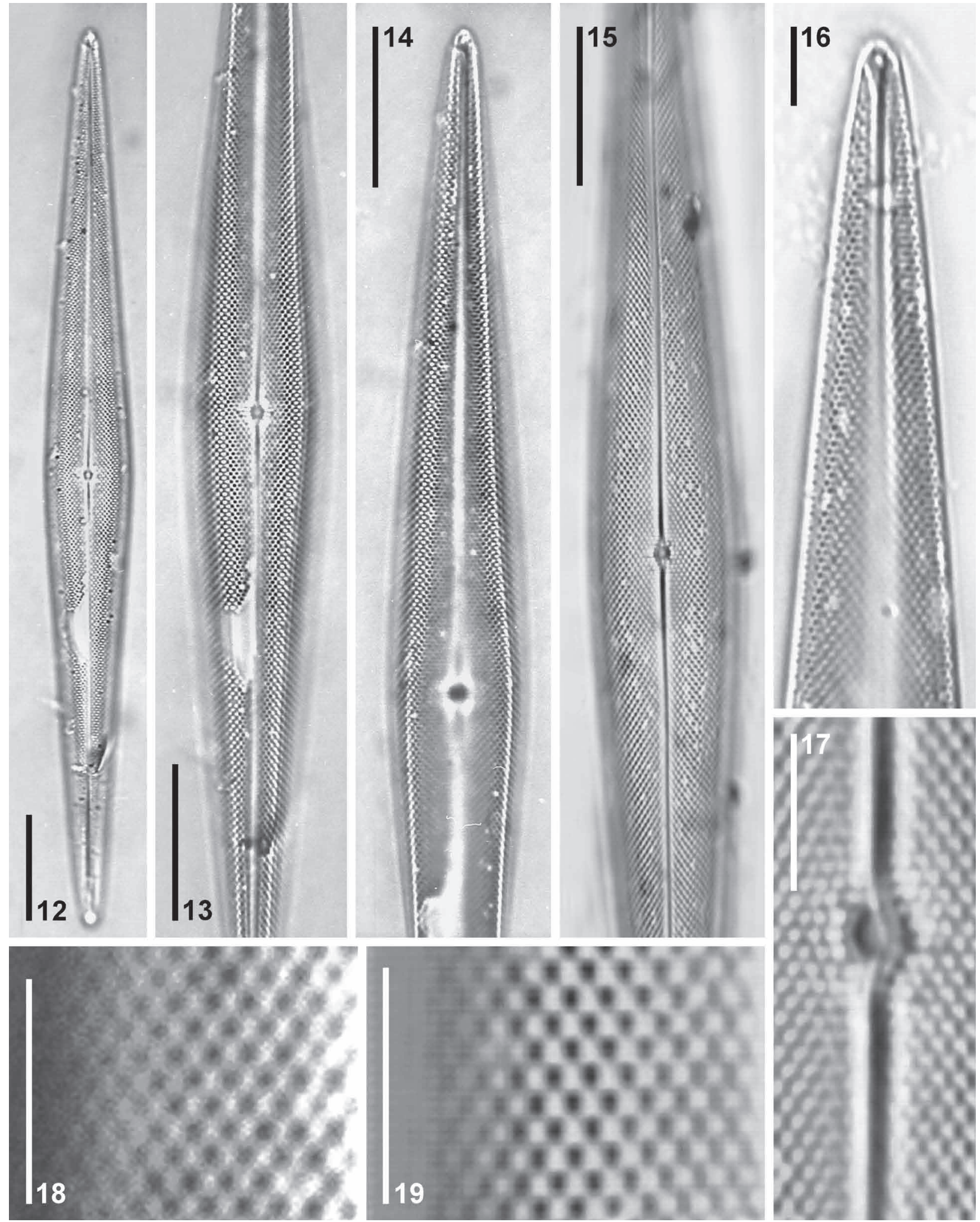

FIGURES 12-19. Pleurosigma acus, LM. 12-14, 18. Lectotype. 15-17, 19. Epitype specimen. All BF. 18, 19. Greatly enlarged detail of lectotype (Fig. 18) and epitype (Fig. 19) striation to facilitate verification of identical stria density and stria angle. Scale bars $=20 \mu \mathrm{m}$ (Figs. 12-15), $5 \mu \mathrm{m}$ (Figs. 16-19). 
Pleurosigma acus A. Mann (1925: 132, pl. 29, figs. 4 and 5) (Figs. 12-19, LM; 20-24, SEM)

=P. subrectum Cleve in Cleve \& Grunow (1880: 53, pl. 3, fig. 72) syn. nov.

Type:-USNM! \#3278 and \#3279, (both selected specimens.) of which \#3278 was designated the syntype in Stidolph (2002) and \#3279 is the lectotype here designated.

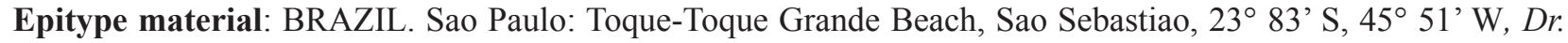
Ricardo Tsukamoto, 30 June 2012, leg. R.Y. Tsukamoto (in collections Sterrenburg \#724 and Herbario Maria Eneyda P.K. Fidalgo, Instituto de Botanica de Sao Paulo \#SP 428.775), here designated.
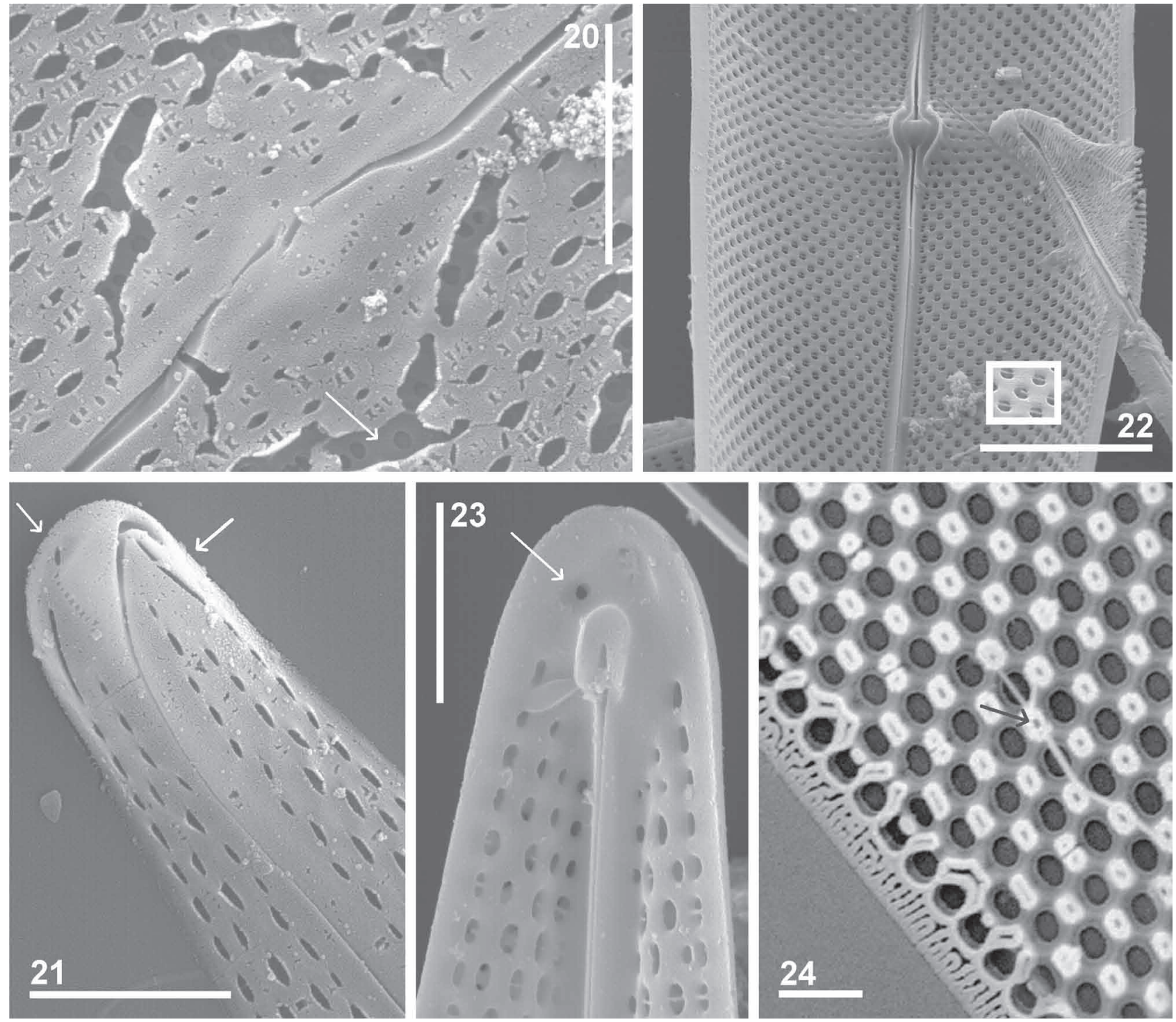

FIGURES 20-24. Pleurosigma acus, epitype material except for Fig. 24, SEM. 20. Valve centre, external. Valve morphogenesis not yet finished, tegumental layer in process of formation. Note absence of septa (arrow). Central raphe fissures almost overlap. 21. Valve apex, external. Left arrow marks apical pore, right arrow marks accessory fissure terminating within raphe "hook". 22. Valve centre, internal. Note double areolar openings (see enlarged inset) and elevated central raphe nodule. 23. Valve apex, internal. Note double areolae. Prominent helictoglossa, arrow (see enlarged inset) marks apical pore. 24. Developing valve, tegumental layer not yet deposited. Specimen from California, USA, examined in Sterrenburg et al. (2005). Note non-loculate valve structure and hollow columns (black arrow at centre). Scale bars $=5 \mu \mathrm{m}$ (Fig. 22), $2 \mu \mathrm{m}$ (Figs 20, 21, 23), $1 \mu \mathrm{m}$ (Fig. 24).

LM description:-Valves fusiform, non-sigmoid (Figs. 12-15), ca.170-250 $\mu \mathrm{m}$ long, ca. 17-22 $\mu \mathrm{m}$ wide, with acute apices. Raphe sternum non-sigmoid throughout but helictoglossae very slightly deflected (Fig. 16). Striae transverse $c a$. 18-20 in $10 \mu \mathrm{m}$, oblique $c a .15-17$ in $10 \mu \mathrm{m}$, stria angle $65-68^{\circ}$ (Figs. 18, 19). Central area small, round (Fig. 17). Central raphe fissures long, almost overlapping and slightly undulating (Fig. 17).

SEM description:-Externally, central raphe fissures long, deflected to the same side, almost overlapping (Fig. 20). Apical raphe fissures sharply deflected and terminally strongly recurving forming a hook (Fig. 21). A long 
accessory fissure terminates within this hook (Fig. 21, right arrow) and there is an accessory apical pore (Fig. 21, left arrow). Internally, areolar openings generally bisected by a small bar (Fig. 22-see also inset, Fig. 23) except around the elevated central raphe nodule, which is enclosed within two small central bars of approximately equal length (Fig. 22). Helictoglossae prominent, slightly deflected, near the tip there is a small apical pore (Fig. 23, arrow). Basal and tegumental layers joined by columns (Fig. 24), which are hollow (black arrow in Fig. 24). There are no septa dividing the valve interior into compartments (Fig. 20, arrow, and Fig. 24).

Habitat:-Littoral marine.

Distribution:- Type material from Philippines, for additional personal observations of specimens matching the type, see under P. subrectum.

Observations:-Figs. 18 (lectotype specimen) and 19 (epitype specimen) illustrate the perfect match as regards striation: identical stria densities and stria angles $\left(c a .68^{\circ}\right)$. From the descriptions of these two taxa it becomes clear that no morphological differences can be demonstrated for P. subrectum and P. acus, including such fine details as the accessory apical fissures and the hollow columns shoring the two layers of the sandwich-structured valves (compare Figs. 11 and 24).

\section{Discussion}

This investigation illustrates the essential role of well-curated collections in studies on taxonomy of the Bacillariophyta, a division of Algae where the number of species has been estimated at 100000 or more. Based on LM and SEM investigations of the type specimens, no qualitative or quantitative differences can be demonstrated for Pleurosigma subrectum Cleve in Cleve \& Grunow and P. acus A. Mann. This leads us to the conclusion that both species are conspecific, thus $P$. acus is a heterotypic synonym of $P$. subrectum.

Although Cleve and Peragallo wrote more than a century ago, in general their work can still be regarded as very valuable, but in the case of $P$. subrectum their information and illustrations are unsatisfactory from a taxonomic perspective. This is especially surprising because the Maasö material contains numerous specimens-as we have found. If no original material had still been extant, P. subrectum would have remained an obscure taxon.

In Mann's treatment of Pleurosigma acus, the data supplied are more detailed, the problem is that they are wrong. The intersection angle of the oblique striae is stated to be so close to $90^{\circ}$ that the transverse striae are "obscure", but from the illustration accompanying the protologue it is already clear that the transverse striae are somewhat more closely spaced than the oblique, but nevertheless clearly visible. In addition, in the original illustration the oblique striae can be measured to intersect at $<70^{\circ}$ instead of Mann's value of "near $90^{\circ}$ ". As far as can be established, the correct values (determined from Mann's original illustrations and in personally collected specimens matching Mann's photomicrographs) were first given in a table comparing the stria intersection angles of various Pleurosigma species in Sterrenburg (1991).

Moreover, Mann specifies the stria densities with very high precision as " 13.5 to 13.8 in $10 \mu \mathrm{m}$ ". This precision is only warranted if the last digit is significant, implying that the puncta can be counted in LM with a precision of 0.1 "dot" in $10 \mu \mathrm{m}$. This is impossible for several reasons: 1) the diffraction LM image of the dots is not sharp enough for such precision, 2) in many cases (including our Pleurosigmas) the number of dots over $10 \mu \mathrm{m}$ can only be estimated because the transverse striae in particular may be much less than $10 \mu \mathrm{m}$ long, 3) in vaulted valves (as in our Pleurosigmas) the dots cannot be all in focus over a distance of $10 \mu \mathrm{m}$ so only an estimate is possible and 4) in all diatoms, stria density varies along the valve, sometimes by as much as $5 \%$.

Mann's extreme precision is therefore misleading, and it is combined with very poor accuracy: in his photomicrographs it is evident that the stria densities are not so unusually coarse for Pleurosigma as Mann claims, and provisional measurements in these images (Sterrenburg 1991) yielded values around 20 in 10 $\mu \mathrm{m}$ for the transverse and about 16 in $10 \mu \mathrm{m}$ for the oblique striae, indicating an error of up to roughly $50 \%$ in Mann's values.

Examination of materials from four collections, in combination with our own materials, thus indicates that instead of two different species, one supposedly arctic, the other supposedly (sub)tropical, a single (morpho)species is involved, with a remarkably wide distribution from Finnmark to the Philippines, West Europe, Brazil and the W. coast of the USA. This would be an interesting case for a comparison of the molecular data for such widely separated populations. Unfortunately, this is beyond the scope of our investigations, but perhaps we may conclude this discussion with a "tongue in cheek" prediction: the differences found may well be of the same order of magnitude as for widely separated populations of the human species-Finns and Philippinos, for instance. 


\section{Emended description of Pleurosigma subrectum Cleve in Cleve \& Grunow}

LM: valves fusiform, non-sigmoid, $c a$. 160-280 $\mu \mathrm{m}$ long, 17-22 $\mu \mathrm{m}$ wide, with acute apices. Raphe sternum nonsigmoid throughout but helictoglossae very slightly deflected. Striae transverse $c a$. 18-21 in $10 \mu$ m, oblique $c a$. 15-18 in $10 \mu \mathrm{m}$, stria angle $63-68^{\circ}$. Central area small, round. Central raphe fissures long, almost overlapping and slightly undulating. SEM: external central raphe fissures long, deflected to the same side, almost overlapping. Apical raphe fissures sharply deflected and terminally strongly recurving forming a hook. Long apical accessory fissure. Isolated accessory apical pore. Internal areolar openings bisected by a small bar except around the elevated central raphe nodule. Nodule enclosed within two small central bars. Helictoglossae prominent, slightly deflected. Basal and tegumental layers joined by hollow columns.

\section{Erratum}

In Sar et al. (2012) it is stated that the stria intersection angle of $P$. acus is 80-90 degrees. This is incorrect and emended here.

\section{Acknowledgements}

We are indebted to Friedel Hinz (Hustedt collection, Bremerhaven) for material of Pleurosigma subrectum and SEM images. Without her assistance, this paper, and many others we have written, would not have been possible. Marianne Hamnede (Stockholm), David Williams (London), Linda Hollenberg and Stanley Yankowski (Smithsonian Museum) also supported us with slides and data. David Williams and Regine Jahn participated in fruitful discussions. Two anonymous reviewers offered helpful comments. Dr. Ricardo Tsukamoto kindly supplied the epitype material of P. acus.

\section{References}

Cleve, P.T. (1894) Synopsis of the naviculoid diatoms, part 1. Kongliga Svenska Vetenskaps Akademiens Handlingar 26 (2): 1-194.

Cleve, P.T. \& Möller, J.D. (1877-1882) Collection of 324 diatom slides with accompanying analyses of A. Grunow. Parts 1-6. Uppsala, $38 \mathrm{pp}$.

Cleve, P.T. \& Grunow, A. (1880) Beiträge zur Kenntniss der Arctischen Diatomeen. Kongliga Svenska Vetenskaps Akademiens Handlingar 17 (2): $1-121$.

Mann, A. (1925) Marine diatoms of the Philippine Islands. United States National Museum Bulletin 1006 (1): 1-182.

Peragallo, H. (1891) Monographie du genre Pleurosigma et des genres alliés. Le Diatomiste 1 (4): 1-16; 1 (5): 17-35.

Sar, E.A., Hinz, F., Sterrenburg, F.A.S., Lavigne, A.S., Lofeudo, S. \& Sunesen, I. (2012) Species of Pleurosigma (Pleurosigmataceae) with lanceolate or slightly sigmoid valve outline. Analysis of type materials. Diatom Research 27 (3-4): 237-253. http://dx.doi.org/10.1080/0269249X.2008.9705766

Smith, W. (1852) Notes on the Diatomaceae; with description of British species included in the genus Pleurosigma. Annals and Magazine of Natural History 2: 1-12.

Smith W. (1853) A synopsis of the British Diatomaceae; with remarks on their structure, functions and distribution; and instructions for collecting and preserving specimens. 1. John Van Voorst, London, $89 \mathrm{pp}$.

Sterrenburg, F.A.S. (1991) Studies on the genera Gyrosigma and Pleurosigma (Bacillariophyceae). Light-microscopical criteria for taxonomy. Diatom Research 6 (2): 367-389. http://dx.doi.org/10.1080/0269249x.1991.9705182

Sterrenburg, F.A.S., Tiffany, M.A. \& Meave del Castillo, M.E. (2005) Valve morphogenesis in the diatom genus Pleurosigma W. Smith (Bacillariophyceae) - Nature's alternative sandwich. Journal of Nanoscience and Nanotechnology 5 (1): 140-145. http://dx.doi.org/10.1166/jnn.2005.012

Sterrenburg, F.A.S., Hamilton, P. \& Williams, D. (2012) Universal coordinate method for locating light-microscope specimens. Diatom Research 27 (2): 91-94.

http://dx.doi.org/10.1080/0269249x.2012.688493

Stidolph, S.R. (2002) Observations and remarks on the morphology and taxonomy of the diatom genera Gyrosigma Hassall and Pleurosigma W. Smith. V. Pleurosigma types of A. Mann (1925): a critical re-investigation. Micropaleontology 48 (3): 273-284. http://dx.doi.org/10.1661/0026-2803(2002)048[0273:OAROTM]2.0.CO;2 